\title{
Discovering Art using Technology
}

\author{
Alexiei Dingli \\ University of Malta, Malta \\ Dylan Seychell \\ St Martin's Institute of Higher Education, Malta \\ Vince Briffa \\ University of Malta, Malta
}

\begin{abstract}
The Selfie project was not only inspired by the long history of the self-portrait, but also intended to create a genealogy between the self-portraits of masters from the Modern art era and the selfie. The project, designed as a walkthrough experience, consisted of three major engagement areas. On entering the space, children were directed into a 'transformation' area - a typical theatrical wardrobe, where they could dress up in a variety of costumes, including hats and wigs. Once garbed, children were given smart phones and led to the area where they could take a selfie with a celebrity such as Gauguin, Cézanne, Monet, Van Gogh, Modigliani and Munch. Finally, they could manipulate the selfie using gesture-based technology and post it online. The attraction proved to be extremely popular and the children who participated were extremely satisfied with the experience.
\end{abstract}

Keywords: Selfie, Gesture, Intelligent Interfaces, Interaction Design, Social Networking

\section{INTRODUCTION}

We are living in a day and age where the word selfie is an integral part of a young person's vocabulary (Senft, 2015). A selfie can be described as a photograph that a person takes of oneself, typically using a mobile device and which is shared via social media. On the other hand, famous personalities such as Van Gogh, Monet, Cezanne, Munch, etc and their contribution towards art is rather unknown to these people. Inspired by the numerous self-portraits in the Modern Art period (Lawrence-Lightfoot, 1997), the Selfie project is a walkthrough where children are exposed to the works of famous artists, they can take selfies with them, edit them and eventually post them online.

The Selfie project was created for ŻiguŻajg ${ }^{1} 2014$. ŻiguŻajg is the annual International Arts Festival for children and young adults in Malta, which has as its vision, that of positioning the creative arts for children and young people at the core of Malta's creative ecology. It has established itself as the most influential and important festival of the arts in its category and this has been achieved through its vision, which sees a demographic normally assumed to be disassociated and detached from art taking center stage in a variety of artistic happenings.

\footnotetext{
${ }^{1}$ http://www.ziguzajg.org
} 
The Selfie Project was one of the most popular attractions hosting an average of 120 visitors per day during the whole duration of the festival. Each visitor had to go through a process that lasted around 30 minutes and was divided, into the following phases.

The first phase was the Transformation phase. Visitors were provided with various props (these included costumes, makeup, wigs, etc.) and they were free to use them. Essentially, the visitors could transform themselves into whatever they wanted in order to express their emotions or to pass on a message.

With this transformation, the visitor could proceed to the second phase where they could take a selfie together with a self-portrait of a celebrity. The celebrities available were cutouts of the following six artists; Vincent Van Gogh, Claude Monet, Paul Cezanne, Edvard Munch, Paul Gauguin and Amedeo Modigliani. A small bio, underneath each artist, was provided to introduce the visitors with their story. Since they were cutouts, the artists could be moved around and the visitors had all the liberty to take the picture in any pose they wanted. Some of them hugged the artist whilst others made funny poses; others took solo pictures whilst some preferred group photos. Essentially they were free to take a selfie in anyway they preferred. We wanted their creation to be inspired by the self-portrait, which was an important creative platform throughout the history of art (Bonafoux, 1985).

Six small sets, inspired by famous paintings were also provided as a backdrop. These backdrops included, Van Gogh's "Bedroom in Arles" 1888, Munch's "The Scream" 1893, Monet's "Water Lilies" 1916, Cezanne's "Still Life with a Ginger Jar and Eggplants" 1890, Gauguin's "Tahitian pastorale" 1898 and Modigliani's "Portrait of a Polish Woman" 1919.

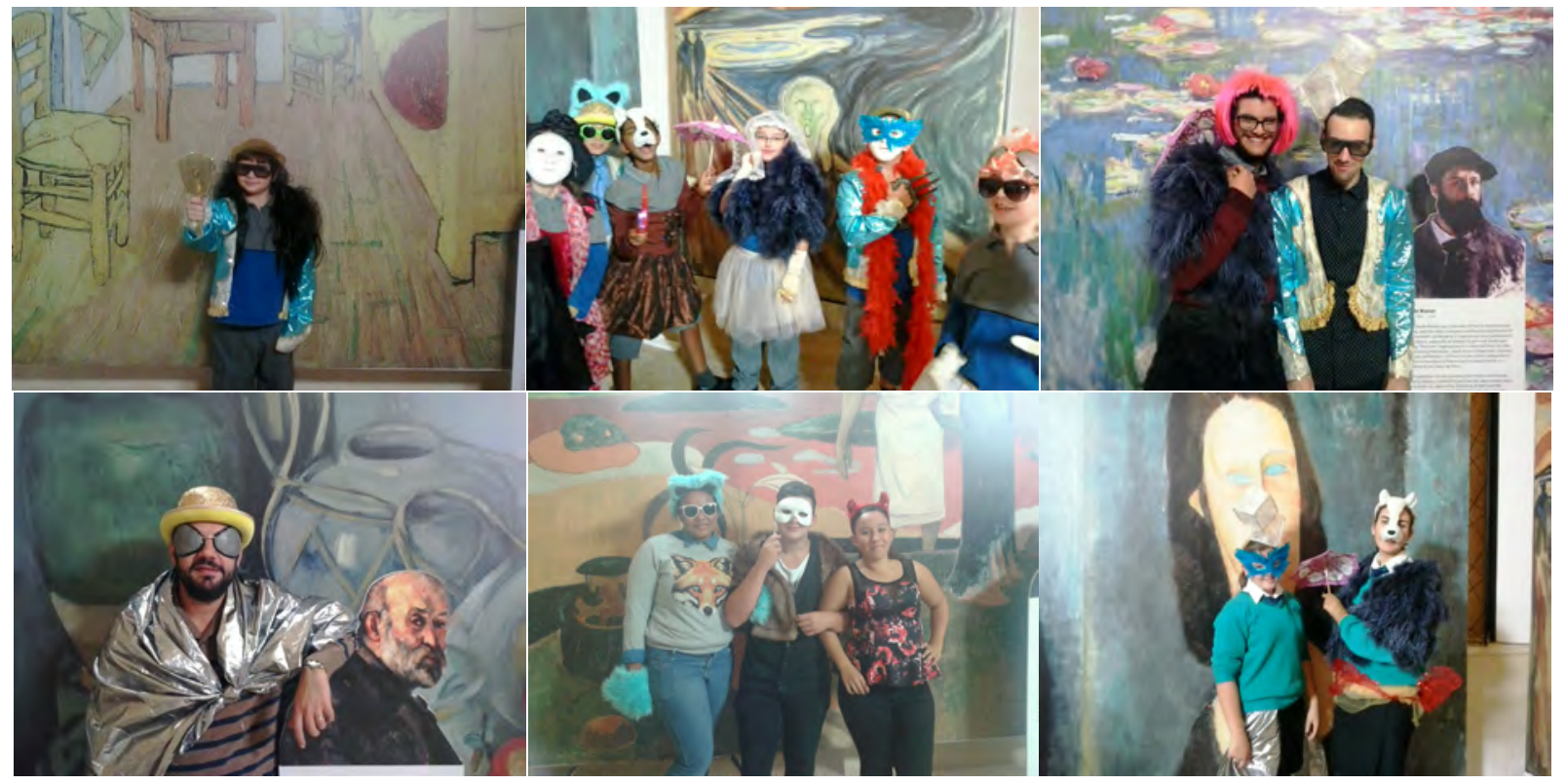

Figure 1: Example Selfies taken with the six paintings, which were provided as backdrop. In some cases, the artist also features in the photo.

The final phase is the manipulation phase where the photos taken were automatically uploaded onto machines, which were provided as part of the exhibit. The visitors could sit down at one of the six terminals and edit their photo. The editing occurred using the Leap Motion controller (Weichert, 2013) (Sutton, 2013) (Vikram, 2013). It senses how one naturally moves his hands and lets the user use the computer using gestures. Visitors were capable of rotating the photos, adjusting their dimensions, 
applying filters (such as sepia, black and white, etc) and undoing their edits. All of this was possible without ever touching the computer, by simply applying gestures in thin air (Garber, 2013). This approach proved to be extremely interesting for both the children and the adults who made use of the system. In fact we have received a lot of positive feedback from the people who used it. When they were happy with the result, they simply posted it to their preferred social networking site such as Facebook (as they are accustomed to do according to (Winter, 2013)) where it was shared amongst their friends.

By going through the selfie walkthrough, the visitor will be able to exit the installation having contributed in a conscious and also experimental manner to the ever-popular art form of the self-portrait. A virtual gallery $^{2}$ was set up to document the project as well as exhibit the self-portraits. An exhibition of etchings from Heritage Malta ${ }^{3}$, $\mathrm{s}$ National Collection was also accompanying the project thus inspiring the young artists and also giving the project a local and historical context.

\section{BACKGROUND}

Art, even the art of fullest scope and widest vision, can never really show us the external world. All that it shows us is our own soul, the one world of which we have any real cognizance ... It is art, and art only, that reveals us to ourselves - Oscar Wilde

What sets the selfie and the self-portrait apart? What are the fundamental differences between the two? Whether carefully staged or totally spontaneous, the selfie has an un-precious quality about it. We do not think twice about throwing away a selfie which, for any odd reason we do not like, as we can always instantly take another. A selfie is impulsive, instinctive, casual and instantaneous, has little or no planning as regards its aesthetic, compositional or other artistic consideration, and is only meant as a frivolous and narcissistic testimony of temporal I-am-ness (de Mönnink, 2014). It is taken primarily in order to be distributed digitally through social media, making an impact on the way we look at ourselves and on the way we perform in public through our body language. Once uploaded, communicating to the world where we are and who we are with, we wait for feedback that is guaranteed to come from those we think are following and others who surprise us.

Selfies therefore are an independent communication and expressive genre, very different from the more systematic and structured self-portrait we are accustomed to in the visual arts. As in the genre of portraiture, they can incorporate a background landscape, activity or occurrence, in order to ground their context. There is no ulterior motive to this inclusion except to reassure the viewing followers of the fact that the "I have really been here" and the "I have really done this" has occurred. The selfie reconfirms one of the very original intentions of photography, that of acting as a proof of occurrence for the whole world to see. In general, selfies do not undergo a post-processing operation. They are not normally digitally retouched or enhanced (Lin, 2014). What is caught by the portable device's camera will either make it to dissemination as is, or not at all as the image gets discarded. This is mainly due to the fact that the maxims that govern the aesthetics of works of art do not feature in this case.

The selfie has popularised the self-portraiture ilk and taken it away from the dominion of the artist. It hits front-page news when taken by a president, the pope or by a celebrity. Broadly speaking, it has even moved away from any art exhibition or gallery structure, which in many cases also necessitates attention to size, printing process, framing and other aesthetics normally associated with the art world, to reside permanently within different social structures in cyberspace. Its method of enjoyment is also different, less formal and more cursory. Unlike self-portraiture, the selfie bears no high-brow presumption. It

\footnotetext{
${ }^{2} \mathrm{https}: / /$ www.facebook.com/ziguzajgselfie

${ }^{3} \mathrm{http}: / /$ heritagemalta.org
} 
carries no burden of figurative or metaphoric undertone and is therefore normally not at the centre of scholarly discourse, at least not just yet; and, totally oblivious of the art market is in no need of curatorial agency. The selfie has undoubtedly become today's most popular genre of self-expression.

This phenomenon has known its beginnings since the time artists first began to scrutinize their own images in the mirror. One notes that like the selfie, which is nearly always taken from within an arm's length of the subject and where the subject is photographed with one or both arms cropped out of the picture, in many a self-portrait, the artist paints himself/herself caught in the act of painting, with palette and brushes in hand.

Although historians have found remains of self-portraits that could be traced back to Ancient Egypt and Ancient Greece, with sculpture, being more durable than fresco or panel painting surviving in greater numbers, the earliest surviving self-portrait painting after Antiquity is thought to be Man in a Red Turban (1433), attributed to the Dutch painter Jan Van Eyck. With the emergence of easel painting and the popularity of oil painting on canvas, the self-portrait both as a distinct, formal category or as images of the artist inserted in other paintings, proliferated, particularly in countries such as Italy, France, the Netherlands, and Spain, during and after the Renaissance.

The self-portrait photograph is as old as the medium. Indeed the first ever recorded is believed to be the self-portrait of Robert Cornelius, a Philadelphia amateur chemist and photographer. This daguerreotype dates back to 1839 and Cornelius is known to have written on its back "The first light picture ever taken. 1839." Throughout the history of photography, self-portraits have documented the often perturbed and troubled artists' inner self. Photographers such as Cindy Sherman (b. 1954), Francesca Woodman (1958 1981) and Nan Goldin (b. 1953) have explored disquieting themes in their self-portraits.

\section{GESTURE-BASED INTERACTION}

To make the selfie project easier for participants, we decided to make use of gesture-based interfaces, a recent addition to interaction paradigms (Dingli, 2015). The advantage of using these interfaces is that the user does not need to make use of a computer keyboard or mouse. This is particularly useful for small children who might not know how to read (Broaders, 2007) (Höysniemi, 2005) (Lee, 2005). However, the use of gestures makes it very easy for everyone to understand and the learning curve involved is very shallow.

To achieve this, we made us of the Leap-Motion controller (Vikram, 2013) (Sutton, 2013). A contactless input device that can be attached to a computer via a USB connection. This device is accompanied by a special software that needs to be installed on the machine which is hosting the device. Users may interact with the machine by means of gestures that are detected by the Leap Motion Controller.

The Leap Motion controller is composed of 2 monochromatic depth cameras and 3 infrared LEDs (Weichert, 2013) that allow for gesture detection within a hemisphere of approximately $1 \mathrm{~m}$. 2D frames from each depth camera are then transmitted to the computer, which then processes the 3D position of the hands detected by the controller. This 3D mapping is then used to recognise gestures that would then be also linked to commands within the system that would be interpreted by third party software such as the image editor developed within the context of this project. The commands are various and include processes like changing filters, cropping images, etc.

\footnotetext{
${ }^{4}$ http://loc.gov/pictures/resource/cph.3g05001/
} 


\section{GESTURES}

The Leap Motion controller allows for different gestures that can be recognised by the system. The most common gestures are the following presented below.

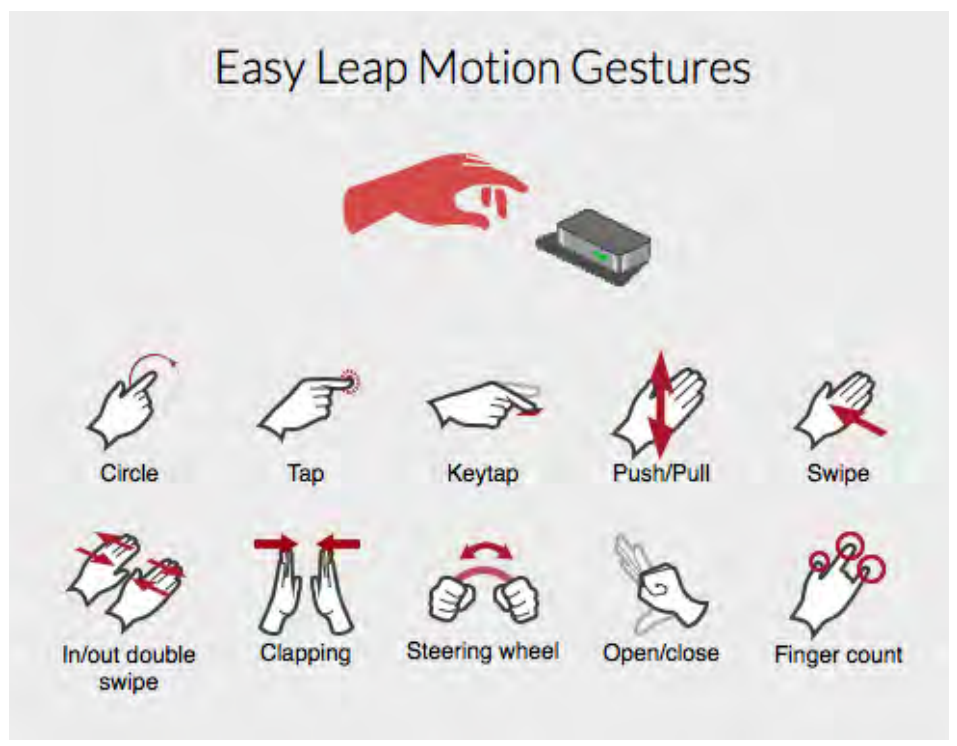

Figure 2: Gestures supported by the Leap Motion controller [Source
http://carlosfernandezmusoles.blogspot.co.uk]

The SDK (Spiegelmock, 2013) (Seixas, 2015) allows for a reasonable access to position data within the 3D space that would therefore enable the developer to also capture new gestures. The versatility of this device is incredible when considering that the controller can detect more than 10 gestures together with a combination of them. Most of them are also rather intuitive. If one considers a Key Tap in thin air, its as if the user is pressing on a virtual keyboard. Same goes for a swipe, a push, etc.

\section{METHODOLOGY}

\section{ARCHITECTURE}

The main components of this system were the mobile application (that enables visitors to take selfies) and the image editing web application that enables the visitors to edit the photographs on a terminal, using the Leap-Motion Controller. This section will briefly explain the setup of the installation.

As illustrated in Figure 3, the selfie application running on the smart-phones would be able to send the photographs to a server where they would be temporarily stored. On the other hand, the terminals with the Leap Motion Controllers connected to them would also be connected to the same server. Through this connection, they connected the server and displayed the web application that allowed for photo editing. Each terminal would fetch the next available photograph and then the user can edit the image as explained below. Once the user is done editing the photographs on the terminals, the systems allows for posting the same selfie to the designated Facebook page. 


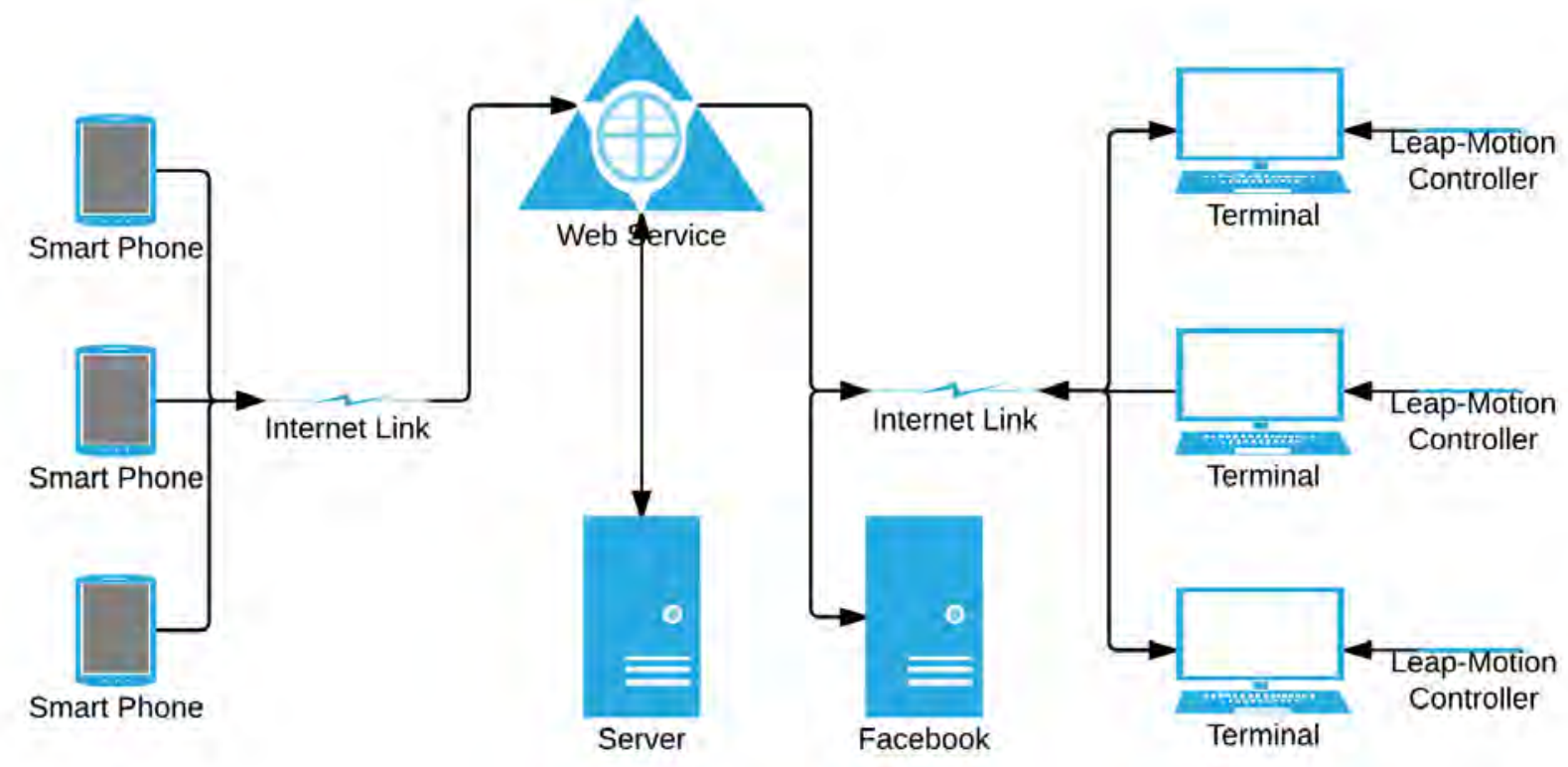

Figure 3: Network Diagram of the installation

\section{INTERACTION DESIGN}

This section aims to outline the Interaction Design process that was undertaken to develop the software for this installation. The process started with a conceptual model that briefly explained the idea and developed into a conceptual design that included a Use-Case Diagram. This was followed by a selection of personas and related scenario that helped the development team reason about the various scenario possible.

\section{CONCEPTUAL DESIGN}

The installation required the user to take a selfie next to a replica of a piece of art and then be able to submit the selfie for editing. On a different device, the user would then be able to edit the photo by applying basic transformations and filters. Subsequently, the user would be able to submit the edited photo to a Facebook page that would act as a screen within the setup. Even though the steps might seem rather straight forward we have to be careful in order to satisfy the needs of the users keeping in mind that they were not restricted in any way. The system could cater for a single selfie or a group selfie. It could include playful interaction with the background or even with the cut-out of the artist. It could include close-ups or wide angle shots. Since we were dealing with young children, we also wanted to ensure that the system was easy to use with a very shallow learning curve. In fact the interaction on the mobile app was extremely minimalistic. The ushers present with the installation also mentioned this fact and declared that most of the children immediately understood how to use the app without having to go through any particular training. 


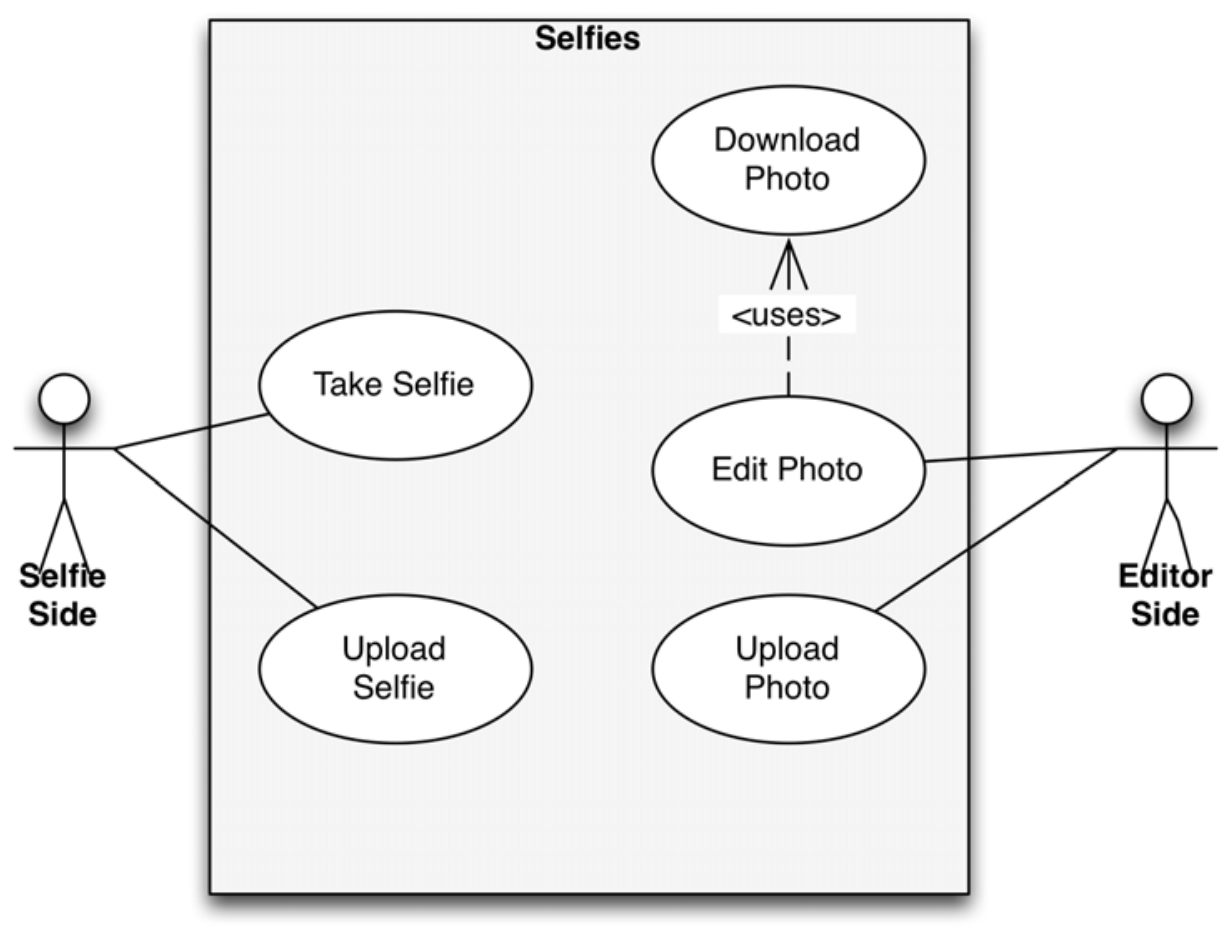

Figure 4: Use Case Diagram of the Installation

The Use Case Diagram (UCD) of the artistic installation in question is presented in Figure 4. In this application, the user experiencing it would in theory assume 2 roles as presented below:

- Selfie-taker: The stage when the user would use the mobile application to take the selfie and upload it for editing.

- Editor: The stage when the user can interact with the terminal to edit the selfie image prior to uploading on Facebook.

Each role requires a different interaction design process. The target audience of users were mostly children who would visit the arts festival. However, it was understood that students would also visit when accompanied by adults whom in practice would be either teachers or parents. Hence, the following personas were drawn during the requirements stage:

\begin{tabular}{|l|l|}
\hline Persona 1: Peter & - Age: 8 \\
& - Gender: Male \\
& - Nationality: Maltese \\
& - Education: Primary School Student \\
& - Occupation/Status: Student \\
\hline Persona 2: Faye & - Age: 7 \\
& - Gender: Female \\
& - Nationality: Maltese \\
& \\
&
\end{tabular}




\begin{tabular}{|c|c|}
\hline & $\begin{array}{ll}\text { - } & \text { Medical Conditions: NA } \\
\text { - } & \text { Occupation/Status: Student }\end{array}$ \\
\hline Persona 3: Christine & $\begin{array}{ll}\text { - } & \text { Age: } 25 \\
\text { - } & \text { Gender: Female } \\
\text { - } & \text { Nationality: Maltese } \\
\text { - } & \text { Education: Tertiary } \\
\text { - } & \text { Medical Conditions: NA } \\
\text { - } & \text { Occupation/Status: Teacher }\end{array}$ \\
\hline Persona 4: Paul & $\begin{array}{ll}\text { - } & \text { Age: } 61 \\
\text { - } & \text { Gender: Male } \\
\text { - } & \text { Nationality: Maltese } \\
\text { - } & \text { Education: Vocational } \\
\text { - } & \text { Medical Conditions: Sight issues } \\
\text { - } & \text { Occupation/Status: Grandparent }\end{array}$ \\
\hline
\end{tabular}

Table 1: Personas describing our intended audience

These personas were used to prepare for different visitors and usage scenarios. From the initial focus groups that were organised, it resulted that the target user group would be mostly interested in the selfies part. Children were more concerned about taking different photos of themselves rather than actually editing them and sharing them. On the other hand, there was a strong interest from older individuals who would accompany the children to actually get the photos edited and shared. There was also an appreciation of the technical exposure of image editing. In fact, the most promising part based on the initial feedback was the gesture based interface. Most of the participants declared that they have never used one of these interfaces; in fact, they didn't even know it was possible. Thus, they were very excited to try it out. Later in this chapter, we will outline the usability issues related to these preliminary observations.

\section{APPLICATION FLOW}

The design of the user interface was organised in 2 parts; the design of the Selfie Mobile App which can be seen in Figure 5 and the design of the Image Editor.

The flow of the mobile application is presented in Figure 6 below. This was simplified in order to ensure that it can be used by practically all users. The only functionality available upon starting the app is to actually take a selfie. Once the photograph was taken, it can either be uploaded or the user may choose to take another one. The effect of the latter would be that of deleting the original selfie and take a new one.
(6)

ฟ

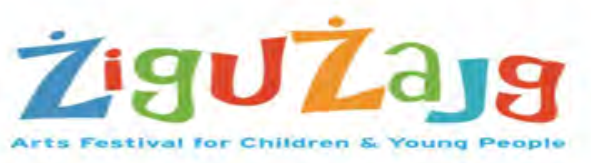

Take Selfie

Figure 5: The Selfie Mobile App Interface 


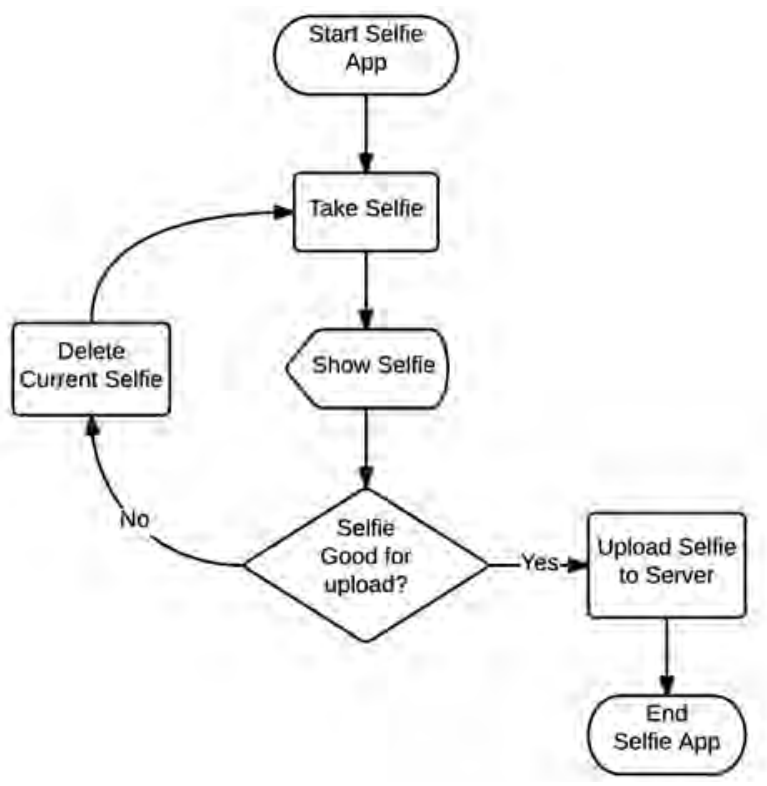

Figure 6: Flowchart of the Selfie Mobile App

Similarly, on the terminals hosting the editors, the users were presented with a simplified solution that facilitates the editing of selfies taken in the previous stage. The flow is illustrated in Figure 7. The selfie editing software was designed to automatically fetch images from the server in order to minimise the interventions required by the user. In fact, users simply sit down and start editing the photograph. The system offers a selection of filters and transformations. The five filters available are Grey scale, Sepia, Brightness adjustment, Blurring or Sharpening and Embossing. Apart from these, the user can also adjust the width and the height of the photo. The only other interaction required by the user is to decide when to post the selfie to the Facebook page after the modifications have been applied.

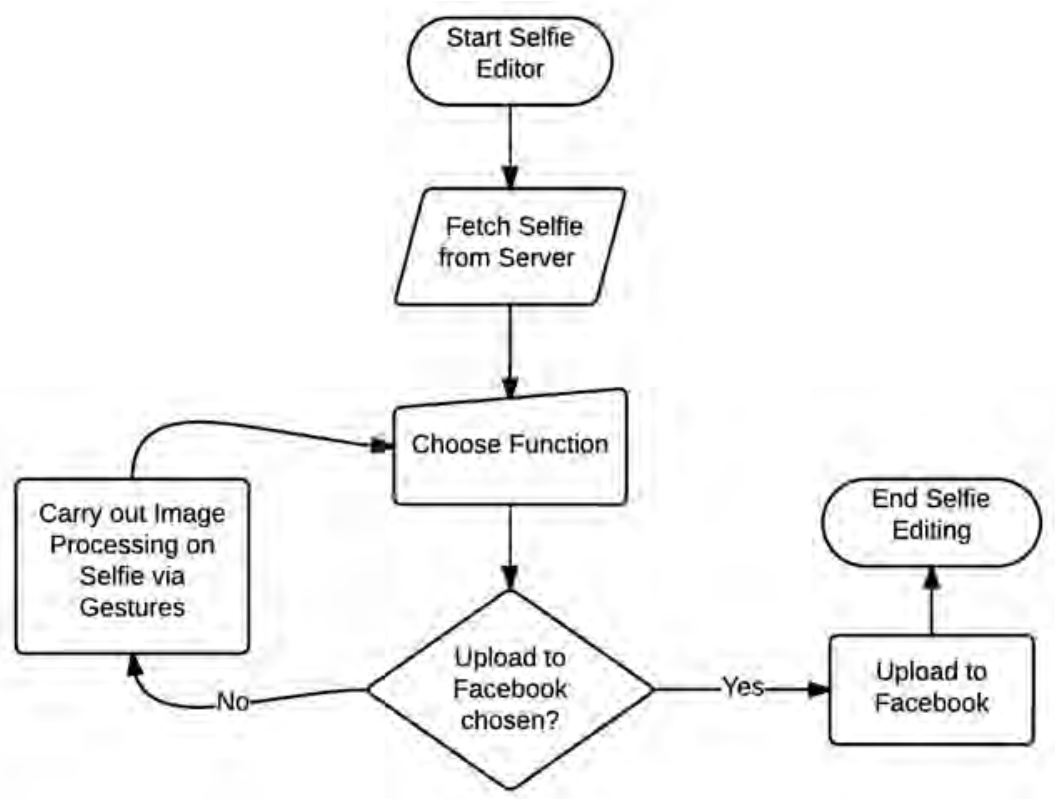

Figure 5: Flowchart of the Selfie Editor 


\section{USER INTERFACE}

As discussed in the previous section, the user interface was kept as simple as possible. Figure 8 shows the screen shot of the system. In the middle, the user is greeted with the photo, which was just taken. This photo was sent to the server through the mobile app and placed in a queue. When one of the six editing terminals becomes available, the picture is automatically loaded and the user who took it sits down in order to start editing it. On the left hand side, we can see a menu made up of the 5 filters mentioned earlier and the two width or height adjustments. The last button is the actual Facebook button, which allows the user to post the image directly. On the right hand side, we find a description pane. This pane is extremely important to provide feedback to the user. One has to keep in mind that in gesture-based interfaces, the user is not given any feedback. This is very different from using a mouse where the mouse pointer is clearly visible on screen or typing on a keyboard with the cursor indicating the position on screen. Because of this, it is very important to provide some sort of reference to the user as indicated in (Manresa, 2005). There are various ways in which we can provide this feedback. It can be made up of simple circles when the hand enters the field of view of the sensor or something more elaborate, like in our case, where the hands were shown as virtual skeletons (See Figure 8) thus giving the user a clear and real-time indication of what he is doing. Even though most of the users were young, the feedback we received was extremely positive. It is clear that our analysis prior to implementing it helped us create an interface which was easy to use yet powerful enough to perform the manipulations necessary.

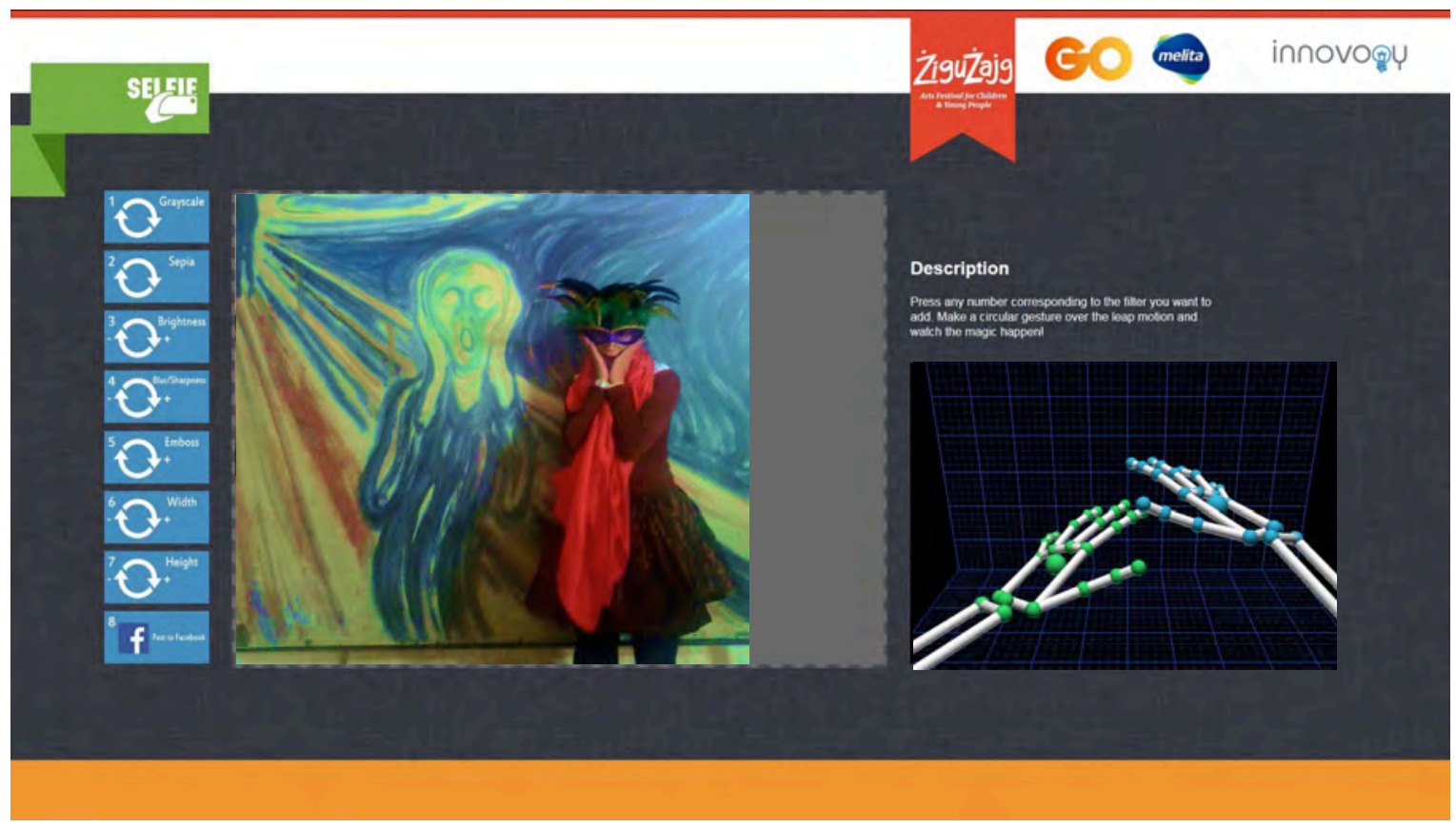

Figure 6: Screenshot of the Selfie Editor

\section{EVALUATION}

To evaluate the system as a whole, we decided to record every step individually. Each phase was then analyzed in order to extract the most relevant information for the project. The evaluation took place between the $17^{\text {th }}$ and $24^{\text {th }}$ November during ŻiguŻajg, the National Children's festival. The majority of the participants during the week were school children that participated in school outings to the festival. In the weekend, most of the children were accompanied by their parents. In total, 974 people participated in 
our project. The real value is much higher but these 974 individuals were those who accepted to be recorded in this study. The average rate amounts to around 120 individuals per day. The system was divided into three phases and we will examine all the phases in the following subsections namely: the transformation phase, the selfie phase and the manipulation phase.

\section{THE TRANSFORMATION PHASE}

The children who visited the installation where first invited to make use of various props in order to express themselves. This is something very common with children since they like to dress up and role play as can be seen in (Fron, 2007) and (Stone, 1990). It is important to keep in mind that most of the visits happened during school days, which means that the students were restricted with their uniform. However there were a couple of days during the weekend where this restriction did not exist. The children could choose between various props which included wigs, masks, pieces of cloths, vests, bras, hats, fans, glasses, plastic toys (such as flowers, arms, cleaning utensils, etc), umbrellas, musical instruments, shirts, tiaras and veils. Most of the participants decided to change their appearance in various ways and very few opted out from this phase. The modifications were various and they reflected the creativity of the children. Furthermore, as can be seen in (Prinstein, 2008), the effect of the social context can be easily noticed since children in particular social dynamics exhibited similar choices. Even though this topic is extremely interesting, it is beyond the scope of this document.

\section{THE SELFIE PHASE}

During the Selfie phase, the children were given a smartphone and asked to take a Selfie. It was noticed that on average, 1.7 people appeared in the photo. This means that most of the photos were actually social expressions within the context of a group since most of the users decided to take a photo with someone else.

It is important to remember that for this experiment we setup six small sets, inspired by famous paintings which were also provided as a backdrop. These backdrops included, Van Gogh's "Bedroom in Arles" 1888, Munch's "The Scream" 1893, Monet's "Water Lilies" 1916, Cezanne's "Still Life with a Ginger Jar and Eggplants" 1890, Gauguin's "Tahitian pastorale" 1898 and Modigliani's "Portrait of a Polish Woman" 1919. The children were free to use whichever set they preferred and their choices were those recorded in Figure 9.

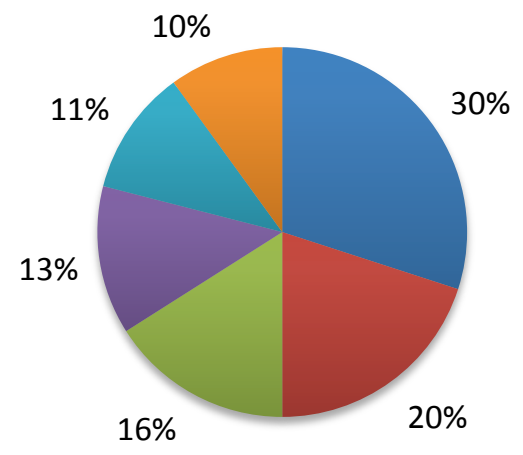

Monet

Van Gogh

Munch

Modigliani

Gauguin

Cezanne

Figure 9: Choice of photos taken 
It is interesting to analyse the choices of these users. Behind them, other blown-up paintings by the same artists provided backdrops for the selfies, in that, for example, if a child selected Vincent van Gogh as his or her buddy, s/he would take the selfie with the background of van Gogh's Bedroom in Arles. This setup, placed the student in the context of van Gogh's world, positioned in between his self-portrait and one of his iconic paintings. The space between the self-portrait cutout and the backdrop image of the painting was calculated bearing in mind the angle of width of the smart phone's lens, in that overshooting was eliminated through restricting the space between the artist's cutout and the background image.

In our case, the overwhelming choice fell on two, Monet's "Water Lilies" and Van Gogh's "Bedroom in Arles". There are various reasons for this. These were the two empty scenes available. There were no people present in these paintings so that users felt that they could experiment better. They sort of considered them as being a blank canvas for their artistic expressions. Van Gogh's painting was less popular than Monet's painting because there was an issue of perspective. The backdrop was higher than the subject of the photo so it was very difficult to get the perspective right. Munch's painting was also quite popular, however some children found it intimidating and the drawing of a person screaming in the scene meant that they did not have the freedom given to them the other two paintings. The other three paintings were substantially less popular with the children. Modigliani's portrait of a polish woman is quite imposing and disproportionate thus making it hard for the children to find an adequate pose. Gauguin's work and Cezanne's still life were rather complex involving many different figures. Thus, it is clear that the children opted for backdrops, which gave them the most freedom.

\section{THE MANIPULATION PHASE}

This was the least popular part with children. They enjoyed using the leap motion controller and applying gestures. The system provided good feedback as per Norman's principles (Norman, 2002) of design by returning a modified images right after a gesture. Help and documentation as per Neilsen's Heuristics (Nielsen, 1995) was also provided in the user interface as demonstrated above. Furthermore, a visualisation tool for the effective use of the leap controller was also employed as shown in Figure 8 to ensure that users can take good command of the system.

Having said that, from the initial experiments prior to the final launch of the installation, it resulted that users were finding it difficult to master a variety of gestures in such a way that would enable them to freely carry out photo editing operations without using other controllers. From these experiments and focus groups, it also resulted that few had the opportunity to try the Leap Motion controller beforehand. With the majority seeing this controller for the first time, it was eventually decided that the system would only capture simple circles gestures in clockwise and anti-clockwise directions. 


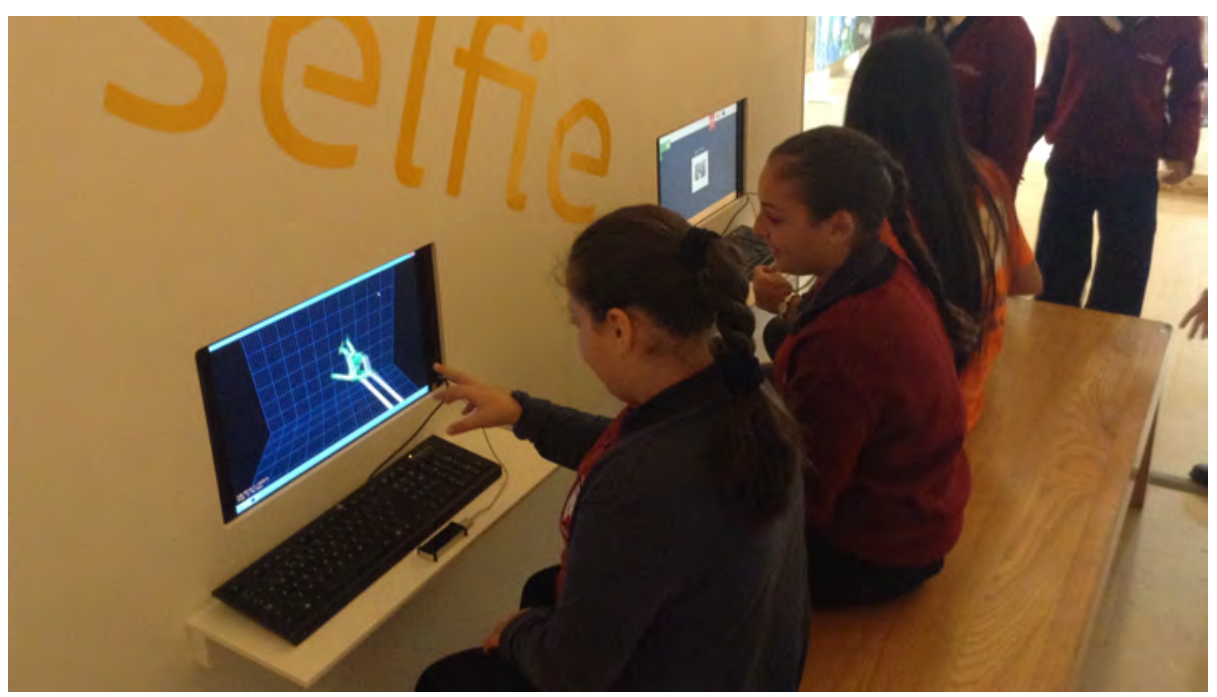

Figure 7: Children using the training visualisation (left) and editing selfies prior to upload (right)

\section{TECHNICAL ISSUES}

The majority of the technical issues experienced were mostly related to the Internet connection of devices. This hindered the image editing functionality since it heavily depended on the Internet connection in order to guarantee the user experience discussed in other sections of this chapter. When children were taking selfies, it was clear that they were enjoying the holistic experience of trying different outfits and posing with the figures in questions.

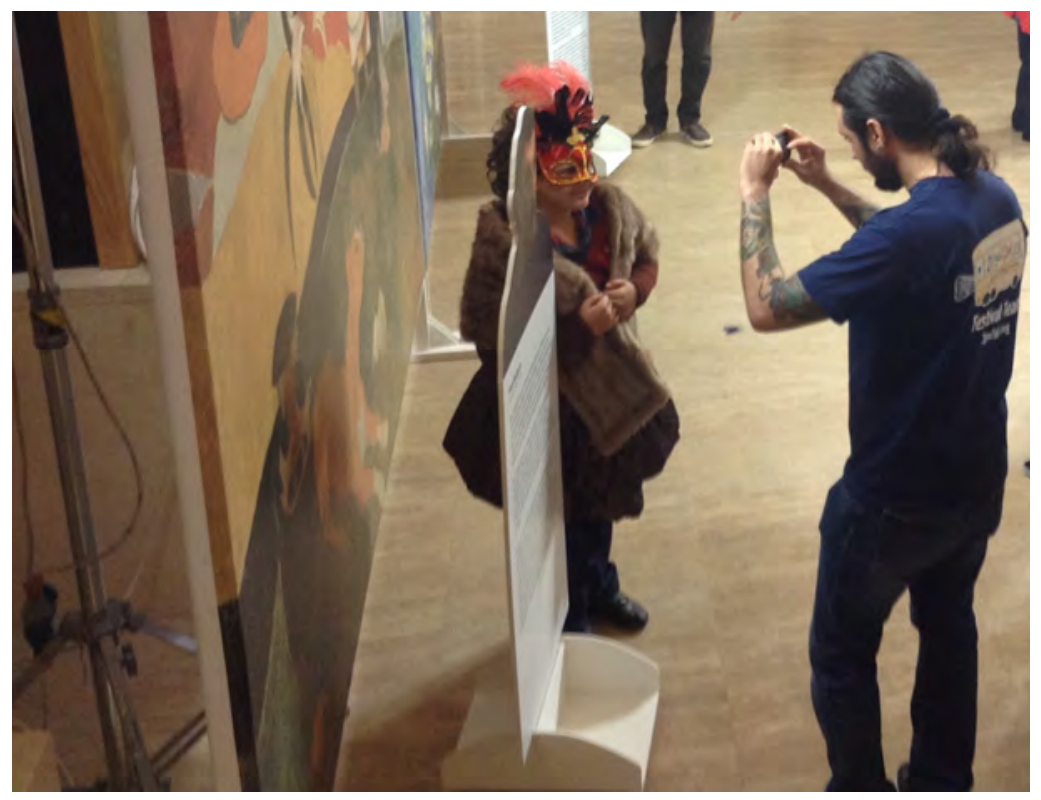

Figure 11: Participants taking photos with artists' figures and back-scene 
It was also clear that the mobile application was intuitive and easy to use. However, due to the costumes and the number of students visiting at any point in time, it was often observed that instead of using the mobile device for selfies, children and guardians were ultimately taking photos with each other's phone (rather than using the one provided by us). When interviewed about this behaviour, respondents explained that they found it difficult to take proper selfies while wearing costumes and trying to include the artists' figures and the back scene.

\section{CONCLUSION}

Overall we were very pleased with the results obtained. In fact, Selfie was one of the most sought after events in ŻiguŻajg 2014. In this paper we presented the underlying architecture while also analyzing the inputs obtained from the participants. In total we received around 120 visitors every day and collected information about their interaction with the system (which amounts to around 500 hours). We had a look at their choices, analysed them as they go through this particular walkthrough and we tried to understand their decisions.

Apart from the analysis part, we also hoped that this experiment made a difference in the life of our participants. Through this experiment, we wanted to help audiences become aware that the self-portrait is not only a product of our times but that it has been around for hundreds of years. In fact, all the artists chosen had created their own self-portrait. We also wanted that this experience presents different realities within the same image, whereby participants will not only be taking the self-portrait but will also undergo the experience of physical transformation in a real and virtual environment, questioning the issue of reality in today's technological world.

\section{ACKNOWLEDGEMENTS}

This project would not have been possible without the support of ŻiguŻajg, the National Children's festival. The team would also like to show its appreciation to the two main Mobile Service providers in Malta, Go ${ }^{5}$ and Melita ${ }^{6}$ for supplying the devices, which were used by the users during the implementation, and testing of the system. We would also like thank Innovogy Ltd for the consultancy provided with regards to the technical aspects, in particular Mr Aldrin Seychell and Mr Mark Bugeja.

\section{REFERENCES}

Bonafoux, P. (1985). Portraits of the artist: the self-portrait in painting. Rizzoli Intl Publishers.

Broaders, S. C.-M. (2007). Making children gesture brings out implicit knowledge and leads to learning. Journal of Experimental Psychology .

de Mönnink, M. I. (2014). Inhabiting the border-A Cultural History of Privacy \& Photography.

Dingli, A. \& Seychell, D. (2015). The New Digital Natives: Cutting the Chord. Springer.

\footnotetext{
${ }^{5} \mathrm{https}: / / \mathrm{www} \cdot$ go.com.mt

${ }^{6} \mathrm{http}: / / \mathrm{www} . \mathrm{melita} . \mathrm{com}$
} 
Fron, J. F. (2007). Playing dress-up: Costumes, roleplay and imagination. Philosophy of Computer Games.

Garber, L. (2013). Gestural technology: Moving interfaces in a new direction. Computer .

Höysniemi, J. H. (2005). Children's intuitive gestures in vision-based action games. Communications .

Lawrence-Lightfoot, S. \&. (1997). The art and science of portraiture. San Francisco: Jossey-Bass.

Lee, S. H. (2005). A gesture-based american sign language game for deaf children. CHI'05 Extended Abstracts on Human Factors in Computing Systems .

Lin, H. W. (2014). Selfie Quality Assessment Based on Angle. IPPR Conference on Computer Vision, Graphics, and Image Processing .

Manresa, C. P. (2005). Hand tracking and gesture recognition for human-computer interaction. ELCVIA: electronic letters on computer vision and image analysis.

Nielsen, J. (1995). Usability inspection methods. Conference companion on Human factors in computing systems.

Norman, D. A. (2002). The design of everyday things. Basic books.

Prinstein, M. J. (2008). Understanding peer influence in children and adolescents. Guilford Press.

Seixas, M. C. (2015). The Leap Motion Movement for 2D Pointing Tasks: Characterisation and Comparison to Other Devices.

Senft, T. M. (2015). Selfies Introduction What Does the Selfie Say? Investigating a Global Phenomenon. International Journal of Communication.

Spiegelmock, M. (2013). Leap Motion Development Essentials. Packt Publishing Ltd.

Stone, G. P. (1990). Appearance and the self: A slightly revised version. Life as theater: A dramaturgical sourcebook.

Sutton, J. (2013). Air painting with Corel Painter Freestyle and the leap motion controller: a revolutionary new way to paint! SIGGRAPH. ACM.

Vikram, S. L. (2013). Handwriting and Gestures in the Air, Recognizing on the Fly. CHI.

Weichert, F. B. (2013). Analysis of the accuracy and robustness of the leap motion controller. Sensors.

Winter, J. (2013). Selfie-loathing. Slate. 